\title{
Correction to: Extracellular Vesicles in Neurodegenerative Diseases: A Double-Edged Sword
}

\author{
Ji Yong Lee ${ }^{1} \cdot$ Han-Soo $\mathrm{Kim}^{2}$ (B)
}

Published online: 18 January 2018

(C) The Korean Tissue Engineering and Regenerative Medicine Society and Springer Science+Business Media B.V., part of Springer Nature 2017

\section{Correction to: \\ Tissue Eng Regen Med (2017) 14(6):667-678 \\ https://doi.org/10.1007/s13770-017-0090-x}

Unfortunately, Acknowledgements section was missing in the originally published article.

It is now provided here as follows:

\begin{abstract}
Acknowledgements In the article 'Extracellular Vesicles in Neurodegenerative Diseases: A Double-Edged Sword' published in Tissue Engineering and Regenerative medicine (Vol 14, Issue 6, Dec. 01, 2017, pp. 667-678) the funding source was omitted. Funding support for this study was obtained from the Bio \& Medical Technology Development Program of the NRF funded by the Korean Government, MSIT (2017M3A9B4042583).
\end{abstract}

The original article can be found online at https://doi.org/10.1007/s13770-017-0090-x.

Han-Soo Kim

hankim63@gmail.com

1 Department of Biomedical Engineering, Catholic Kwandong University, 24 Beomil-ro, 579beon-gil, Gangneung-si,

Gangwon-do 25601, Republic of Korea

2 Department of Biomedical Sciences, College of Medical Convergence, Catholic Kwandong University, 24 Beomil-ro 579beon-gil, Gangneung-si, Gangwon-do 25601, Republic of Korea 